\title{
Patterns and Factors Associated With Respiratory Care Protocol Use
}

\author{
Ashley Y Metcalf PhD, James K Stoller MD MSc FAARC, Timothy D Fry PhD, and \\ Marco Habermann PhD
}

\begin{abstract}
BACKGROUND: Organizational factors associated with adoption and use of respiratory care protocols have received little attention. This study examines patterns of protocol use and features of a hospital and providers that are associated with respiratory care protocol use. METHODS: Forty-four hospitals and their health-care providers responded to an online survey regarding perceived outcomes of protocol use and their level of support for using protocols. Hospital features (ie, size, teaching status, and use of information systems) were also assessed. Descriptive statistics and multivariate logistic regression were used for analysis. RESULTS: Of the 9 types of respiratory care protocols assessed (ie, asthma, COPD, ARDS, hypoxemia, pneumonia, noninvasive ventilation therapy, supplemental oxygen titration and discontinuation, ventilator weaning, and bronchopulmonary hygiene), the most commonly used were for oxygen titration and ventilator weaning. Large hospitals ( $>350$ beds) used protocols more widely than smaller hospitals $(P=.01)$. Respondents felt that use of protocols enhanced cost and quality of care. Finally, hospital features that were associated with overall protocol use were stakeholder support for protocol use and use of high-quality hospital information systems. CONCLUSIONS: The study extends prior research by clarifying features of hospitals and providers associated with use of respiratory care protocols. Validation in future hypothesis-testing samples will further advance this knowledge. Key words: empowerment; respiratory care; protocols; quality; information systems; empirical research; organizational study. [Respir Care 2015;60(5):636-643. () 2015 Daedalus Enterprises]
\end{abstract}

\section{Introduction}

It has been suggested that future demand for respiratory care services will increase, respiratory care costs will increase, and there will be a shortage of skilled respiratory caregivers. ${ }^{1}$ In fact, the Bureau of Labor Statistics suggests that demand for respiratory therapists (RTs) will grow by

Drs Metcalf and Habermann are affiliated with the College of Business, Ohio University, Athens, Ohio. Dr Stoller is affiliated with the Education Institute and Respiratory Institute, Departments of Pulmonary and Critical Care Medicine, Cleveland Clinic, Cleveland, Ohio. Dr Fry is affiliated with Moore School of Business, University of South Carolina, Columbia, South Carolina.

The authors have disclosed no conflicts of interest.

Correspondence: Ashley Y Metcalf PhD, College of Business, Ohio University, 306 Copeland Hall, Athens, OH 45701. E-mail: metcalfa@ ohio.edu.

DOI: $10.4187 /$ respcare.03699
$19 \%$ from 2012 to 2022, which far exceeds average job growth rates. ${ }^{2}$ In a time when the demand and costs for respiratory care services are increasing, there is a clear need for formal and efficient systems that can optimize care while also lowering costs and balancing supply and demand. One such system of care may be the use of RTdriven protocols, also called respiratory care protocols. The use of respiratory care protocols has been shown to enhance the quality of respiratory care and reduce the misallocation of respiratory care resources. ${ }^{3-10}$ Despite these demonstrated benefits, adoption of such protocols has been variable. Although many RTs and managers understand and possibly use individual protocols, few hospitals have implemented a comprehensive respiratory care protocol service, such as a fully developed and implemented assess and treat system. ${ }^{10}$

The wide disparity in the use of respiratory care protocols across hospitals prompts the question of what environmental factors are associated with their adoption and use, which to date has received little attention. ${ }^{11}$ To our knowledge, the only study to examine this issue showed 
that respiratory therapy departments that were deemed change-avid were more likely to use respiratory care protocols than were change-averse departments. ${ }^{11}$

\section{See the Related Editorial on Page 757}

To more fully understand the factors associated with the use of respiratory care protocols, we examined their use within hospital units across a spectrum of hospital and unit types. Furthermore, we compared systemic features of hospitals using such programs versus others in which respiratory care is delivered using a more traditional physiciandirected approach. Three features that we specifically examined within hospitals included: the use of quality management practices, the use of a standardized and integrated information system, and the level of organizational and clinician support for respiratory care protocol use. Other questions that we examined include: (1) What are the differences between hospital units that are high versus low users of protocols? (2) To what degree does key stakeholder support for protocol use (eg, by physicians, RT managers, and RTs on the hospital unit) differ between hospital units using respiratory care protocols versus those not using such protocols? (3) What are the opinions of these stakeholder groups regarding the advantages and disadvantages of respiratory care protocols versus physiciandirected care? This study furthers available research by considering multiple hospital and health-care provider characteristics as correlates of respiratory care protocol use.

\section{Methods}

The study was approved as exempt from written consent by the institutional review board of the University of South Carolina; all participants granted verbal informed consent to participate. Eligible hospitals for the study were United States acute care, non-government hospitals. Within such hospitals, the level of analysis was the individual hospital unit, of which 4 types were analyzed: the ICU, emergency department, adult in-patient unit, and neonatal ICU.

Several organizational features were used to assess an association with respiratory care protocol use: level of organizational support for using respiratory care protocols, adoption of a standardized and integrated hospital information system, use of various quality management practices, and general opinions from stakeholders (eg, physicians, RTs, and RT managers) regarding the benefits and outcomes of protocol use. Measures were assessed using online questionnaires, several of which were previously validated scales, ${ }^{12-14}$ whereas others were designed specifically for this study. In other instances, because of different hierarchical levels and responsibilities within the hospital and potential differences in the perceptions of

\section{QUICK LOOK}

\section{Current knowledge}

Labor statistics suggest that the future demand for respiratory care services will increase, respiratory care costs will increase, and there will be a shortage of skilled respiratory therapists (RTs). An increased demand for respiratory care services requires formal and efficient systems that can optimize care while lowering costs and balancing supply and demand. One such system of care may be the use of RT-driven protocols.

\section{What this paper contributes to our knowledge}

Larger hospitals reported using respiratory therapy protocols more often than small hospitals, but there was no difference between teaching and non-teaching hospitals. There was agreement that the use of protocols lowered costs, improved patient satisfaction, and quality. Different stakeholders disagreed on the impact of protocols on RT workload. The features most strongly associated with protocol use were physician support and a high-quality hospital information system.

protocols, online surveys were designed for and administered separately to each of these stakeholder groups (physicians, RT managers, and RTs).

Overall use was measured as the percentage of patients $(0-100 \%)$ within each unit who were treated according to an RT-directed respiratory care protocol. Nine different types of respiratory care protocols were considered, including condition-specific protocols (ie, asthma, COPD, ARDS, hypoxemia, and pneumonia) and treatment-specific protocols (noninvasive ventilation therapy, supplemental oxygen titration and discontinuation, ventilator weaning, and bronchopulmonary hygiene). For each type of protocol, respiratory care managers were asked to rate the degree of use of the specific protocol using a 5-point Likert scale (where $5=$ always use and $1=$ never use). Stakeholder support for using a comprehensive system of respiratory care protocols within a hospital unit was also assessed. Specifically, all survey respondents were asked whether "physicians (or RT managers/RTs) in this hospital unit support a therapist assess and treat program for this unit," where $5=$ strongly agree and $1=$ strongly disagree.

Organizational support was defined as the respondent's impression about the hospital's general support for process improvement and empowerment programs and was measured based on a validated instrument. ${ }^{14}$ Specific questions to assess organizational support included: "This hospital: (1) has an explicit goal to improve processes for patient care; (2) has an explicit goal to focus on increasing value 


\section{Patterns and Factors in Respiratory Care Protocol Use}

Hospital Unit: (1) ER, (2) ICU, (3) NICU, (4) Adult in-patient

Assess and Treat Usage [manager, physician]

(1) What percentage (\%) of patients in this unit are typically assigned orders of RT "Assess and Treat"?

(2) How often are therapist driven protocols used: (1 - never, 3 - sometimes, 5 - always)

Support from key participants [manager, physician, therapist]

Responses: 1 - strongly disagree $\rightarrow 5$ - strongly agree

(1) I am personally in favor of a therapist-driven Assess and Treat system for respiratory care in this unit

(2) The group of physicians in this unit are in favor of a therapist-driven Assess and Treat system for respiratory care

(3) The respiratory care management over this unit are in favor of a therapist-driven Assess and Treat system for respiratory care

(4) The respiratory therapists that work in this unit are in favor of a therapist-driven Assess and Treat system for respiratory care

Organizational Support [manager]

Responses: 1 - strongly disagree $\rightarrow 5$ - strongly agree

This hospital...

(1) has an explicit goal to improve processes for patient care ${ }^{14}$

(2) has an explicit goal to focus on increasing value to the patient ${ }^{14}$

(3) is open and responsive to change ${ }^{14}$

(4) empowers frontline caregivers to make treatment decisions (new)

Information Systems ${ }^{13}$ [manager]

Responses: 1 - strongly disagree $\rightarrow 5$ - strongly agree

(1) Our electronic information systems are standardized across departments

(2) Our electronic information systems are integrated across departments

(3) Our electronic information systems support frontline employees

(4) Both hardware and software are reliable

(5) Electronic information systems are used to link caregivers actions with patient outcomes

Quality Practices ${ }^{12}$ [manager]

Responses: 1 - never, 3 - sometimes, 5 - always

To what extent are these elements used at your hospital:

(1) Patient satisfaction data collection by surveys, focus groups, etc.

(2) Quality improvement teams comprised of hospital employees

(3) Statistical quality or process control using control charts, etc.

(4) Competitive benchmarking of best-in-class processes

Protocol Outcomes Assessment [manager, physician, therapist]

Assess the impact to the following outcomes when patients are treated under a therapist-driven protocol compared to a

physician-driven system: (1 - much lower; 3 - no change; 5 - much higher)

(1) Cost of patient treatment

(2) Quality of patient care

(3) Job satisfaction of RTs

(4) Workload for RTs

(5) Workload for physicians

(6) Patient satisfaction

(7) Job satisfaction of physicians

Fig. 1. Survey questions [survey respondents in brackets]. ER = emergency room; NICU = neonatal ICU; RTs = respiratory therapists.

to the patient; (3) is open and responsive to change; and (4) empowers frontline caregivers to make treatment decisions." Impressions about the use of information systems were measured using a validated instrument, ${ }^{13}$ which addressed the availability, standardization, integration, and use of information systems in a hospital (5-point scale, where $5=$ strongly agree and $1=$ strongly disagree). Quality practices were measured using an established instrument ${ }^{12}$ regarding the use of tools, policies, and behaviors by a hospital unit to achieve quality-improvement goals. These were captured using a 4-item scale regarding the use of competitive benchmarking, statistical process controls, quality-improvement teams, and patient satisfac- tion. Stakeholder opinions regarding respiratory care protocol use considered respondents' impressions about the impact of protocol use on the cost of care, quality of care, job satisfaction for RTs, work load for RTs, job satisfaction for physicians, work load for physicians, and patient satisfaction, compared with a traditional physician-driven respiratory care order system (Fig. 1).

For each hospital unit assessed, a survey was administered to at least one member of each stakeholder group. Participating hospitals and stakeholders were recruited in various ways. First, the principal investigator (AYM) attended and presented the general research idea at the annual state conferences for the North Carolina Society for 


\section{Patterns and Factors in Respiratory Care Protocol Use}

Respiratory Care and the South Carolina Society for Respiratory Care, inviting interested attendees to participate. Second, an announcement of the study was sent by the American Association for Respiratory Care to its list of respiratory care managers with an invitation to interested parties to contact the principal investigator, who then contacted each interested manager to explain the study and assess interest in participating. Hospital and RT manager anonymity was ensured.

Notably, participating RT managers were critical participants and research collaborators, as they were responsible for identifying participants in their hospital, distributing online surveys within their hospital, and following up on responses. Within each hospital, attempts were made to engage participants from each of the hospital units being studied (ie, emergency department, ICU, neonatal ICU, and adult in-patient unit), if appropriate for that hospital. To encourage participation, weekly reports of current response rates from each hospital unit were provided to each participating RT manager.

After data collection was complete, the scales used in the study were tested for reliability and validity by performing a confirmatory factor analysis and measuring Cronbach's alpha (all $>.8$ ) and several goodness-of-fit indices: root mean square error of approximation, comparative fit index, standardized root mean square residual, and coefficient of determination. These scales included organizational support, information systems, and quality practices. Use of protocols, stakeholder opinions of outcomes, and stakeholder support for respiratory care protocol use were all captured by single-item measures and therefore not amenable to reliability and validity testing.

Dichotomous analyses were stratified according to whether respiratory care protocols were used (yes/no), by specific protocol type, and by the level of use (high vs low), where high use indicated that $>60 \%$ of patients received care on the hospital unit according to a respiratory care protocol and low use indicated that between 5\% and $50 \%$ of patients were treated by a protocol. No hospital units in our sample indicated a level of protocol use of between 50 and $60 \%$. Analyses also considered hospital features: size (defined by the number of in-patient beds) and teaching versus non-teaching status (both according to the American Hospital Association, http://www.ahadata viewer.com, Accessed March 15, 2013).

Logistic regression was used to identify significant differences between users and non-users of respiratory care protocols, accounting for hospital features and stakeholder responses. Results are expressed as odds ratios, ${ }^{15}$ reflecting the odds of being a user versus a non-user of protocols and a high-level versus a low-level user. Statistical analyses were performed using Stata 13 (StataCorp, College Station, Texas).
Table 1. Characteristics of Participating Hospitals

\begin{tabular}{|c|c|c|c|}
\hline Hospital ID & Teaching & Size (No. of Beds) & Units Participating \\
\hline A & Yes & 256 & $\mathrm{ICU}, \mathrm{ED}, \mathrm{AI}$ \\
\hline B & No & 25 & $\mathrm{ED}, \mathrm{AI}$ \\
\hline $\mathrm{C}$ & Yes & 395 & AI \\
\hline D & No & 197 & $\mathrm{ED}, \mathrm{AI}$ \\
\hline $\mathrm{E}$ & Yes & 360 & $\mathrm{ICU}$ \\
\hline $\mathrm{F}$ & Yes & 303 & $\mathrm{ICU}, \mathrm{ED}, \mathrm{AI}$ \\
\hline G & No & 350 & ICU, AI \\
\hline $\mathrm{H}$ & No & 450 & ICU, NICU, ED, AI \\
\hline I & Yes & 190 & ICU, ED, AI \\
\hline $\mathrm{J}$ & Yes & 344 & ICU, NICU, ED, AI \\
\hline K & Yes & 524 & ICU, NICU \\
\hline $\mathrm{L}$ & Yes & 172 & $\mathrm{ICU}, \mathrm{ED}, \mathrm{AI}$ \\
\hline M & Yes & 1,267 & ICU, AI \\
\hline $\mathrm{N}$ & No & 260 & $\mathrm{ED}, \mathrm{AI}$ \\
\hline $\mathrm{O}$ & Yes & 303 & ICU, NICU, ED, AI \\
\hline $\mathrm{P}$ & Yes & 681 & ICU, NICU, ED, AI \\
\hline Q & Yes & 308 & ICU, NICU, ED, AI \\
\hline $\mathrm{R}$ & No & 340 & ICU, ED, AI \\
\hline S & Yes & 475 & ICU, AI \\
\hline $\mathrm{T}$ & No & 86 & ICU \\
\hline $\mathrm{U}$ & No & 82 & $\mathrm{ED}, \mathrm{AI}$ \\
\hline V & No & 106 & $\mathrm{ICU}, \mathrm{ED}, \mathrm{AI}$ \\
\hline W & Yes & 1,637 & ICU, AI \\
\hline $\mathrm{X}$ & Yes & 152 & ICU, AI \\
\hline Y & Yes & 783 & ICU, NICU, ED, AI \\
\hline Z & No & 377 & $\mathrm{ICU}, \mathrm{ED}, \mathrm{AI}$ \\
\hline $\mathrm{AA}$ & Yes & 637 & ICU, NICU, ED, AI \\
\hline BB & Yes & 979 & ICU, NICU, ED, AI \\
\hline $\mathrm{CC}$ & Yes & 420 & ICU, NICU, ED, AI \\
\hline DD & Yes & 712 & NICU \\
\hline $\mathrm{EE}$ & Yes & 103 & AI \\
\hline FF & Yes & 116 & $\mathrm{ICU}, \mathrm{AI}$ \\
\hline GG & No & 286 & ICU, ED, AI \\
\hline $\mathrm{HH}$ & No & 325 & ICU \\
\hline II & Yes & 238 & $\mathrm{ICU}, \mathrm{ED}, \mathrm{AI}$ \\
\hline JJ & No & 203 & ICU, AI \\
\hline KK & No & 121 & ICU \\
\hline LL & No & 110 & ICU, ED, AI \\
\hline MM & Yes & 514 & ICU, NICU, ED, AI \\
\hline $\mathrm{NN}$ & No & 215 & ICU, AI \\
\hline $\mathrm{OO}$ & No & 134 & ICU \\
\hline PP & Yes & 530 & $\mathrm{ICU}, \mathrm{ED}, \mathrm{AI}$ \\
\hline QQ & No & 365 & ICU, NICU, AI \\
\hline $\mathrm{RR}$ & Yes & 921 & ICU \\
\hline \multicolumn{4}{|c|}{$\begin{array}{l}\mathrm{ED}=\text { emergency department } \\
\mathrm{AI}=\text { adult in-patient unit } \\
\mathrm{NICU}=\text { neonatal ICU }\end{array}$} \\
\hline
\end{tabular}

\section{Results}

Participating hospitals varied in size from 25 to 1,637 beds (mean \pm SD of $405 \pm 279$ ), with $59 \%$ being teaching hospitals (Table 1). Of the 61 hospitals that initially 


\section{Patterns and Factors in Respiratory Care Protocol Use}

Table 2. Patterns of Respiratory Care Protocol Use for All Included Units (105 Units, Manager Survey)

\begin{tabular}{lccc}
\hline \hline \multirow{2}{*}{ Protocol } & \multicolumn{2}{c}{ Level of Protocol Use (\%) } \\
\cline { 2 - 4 } & Never & Infrequent & Frequent \\
\hline Condition-specific protocols & 26 & 29 & \\
$\quad$ Asthma & 28 & 23 & 50 \\
COPD & 38 & 27 & 35 \\
ARDS & 22 & 23 & 54 \\
Hypoxemia & 30 & 23 & 47 \\
Pneumonia & & & \\
Treatment-specific protocols & 26 & 25 & 49 \\
$\quad$ Noninvasive ventilation therapy & 13 & 23 & 64 \\
Oxygen titration and discontinuation & 20 & 23 & 57 \\
Ventilator weaning & 28 & 35 & 37 \\
Bronchopulmonary hygiene & &
\end{tabular}

agreed to participate in the study, responses from at least 2 different stakeholder types were received from 44 hospitals $(66 \%)$. In total, usable responses were received from 105 RT managers, 79 physicians, and 571 RTs. Furthermore, the number of participating units with at least 2 stakeholders represented included 37 ICUs, 13 neonatal ICUs, 25 emergency departments, and 36 adult in-patient units.

The results in Table 2 show that oxygen titration and discontinuation and ventilator weaning protocols were most frequently used (64\% and $57 \%$, respectively), where "frequent use" bundles stakeholder responses of "often" and "always" and "infrequent use" bundles responses of "rarely" and "sometimes." Overall, nearly half of the participating hospitals were frequent users of 7 of the 9 protocols surveyed, with protocols for ARDS and pneumonia used least frequently (38\% and $30 \%$ of hospitals, respectively).

Teaching hospitals reported a non-significant trend toward using treatment-specific protocols more frequently and condition-specific protocols less frequently than nonteaching hospitals (Table 3). The overall use of protocols was significantly greater in larger hospitals than in smaller hospitals $(P=.01)$. Furthermore, larger versus small hospitals (Table 4) were statistically different in their use of protocols for asthma $(P=.02)$, ARDS $(P=.02)$, hypoxemia $(P=.01)$, oxygen titration and discontinuation $(P=.03)$, ventilator weaning $(P=.02)$, and bronchopulmonary hygiene $(P=.07)$.

Table 5 presents the impressions of different stakeholder groups (physicians, RT managers, and RTs) regarding the impact of protocol use versus physician-directed care. All groups felt that protocol use lowered the cost of care, improved quality, enhanced RT and physician satisfaction, lowered physician work load, and enhanced patient satisfaction. Impressions regarding the impact of protocol use on RT work load differed between groups, with RTs equally divided among those believing work load increased (37\%), decreased $(31 \%)$, or remain unchanged $(32 \%)$, but most physicians (54\%) believed that RT work load increased, and the plurality of RT managers $(42 \%)$ believed that RT work load decreased.

Table 6 presents the results of logistic regression analysis of factors associated with respiratory care protocol use. Odds ratios (ORs) for using protocols significantly exceeding 1 (ie, positively associated with protocol use) were observed for physician support $(\mathrm{OR}=3.68, P<.01)$ and for use of high-quality hospital information systems $(\mathrm{OR}=2.33$, $P=.03$ ), with a trend toward protocol use being associated

Table 3. Use of Respiratory Care Protocols Stratified by Hospital Teaching Status (105 Units, Manager Survey)

\begin{tabular}{|c|c|c|c|c|c|c|}
\hline \multirow[b]{3}{*}{ Protocol } & \multicolumn{6}{|c|}{ Level of Use (\%) } \\
\hline & \multicolumn{2}{|c|}{ Never } & \multicolumn{2}{|c|}{ Infrequent } & \multicolumn{2}{|c|}{ Frequent } \\
\hline & Teaching & Non-Teaching & Teaching & Non-Teaching & Teaching & Non-Teaching \\
\hline \multicolumn{7}{|l|}{ Condition-specific protocols } \\
\hline Asthma & 25 & 27 & 37 & 17 & 38 & 57 \\
\hline COPD & 29 & 26 & 24 & 19 & 47 & 55 \\
\hline ARDS & 30 & 54 & 34 & 14 & 36 & 32 \\
\hline Hypoxemia & 25 & 17 & 27 & 17 & 47 & 67 \\
\hline Pneumonia & 29 & 32 & 27 & 14 & 43 & 54 \\
\hline \multicolumn{7}{|l|}{ Treatment-specific protocols } \\
\hline Noninvasive ventilation therapy & 33 & 15 & 20 & 33 & 48 & 52 \\
\hline Oxygen titration and discontinuation & 18 & 6 & 12 & 38 & 69 & 56 \\
\hline Ventilator weaning & 20 & 19 & 24 & 22 & 55 & 59 \\
\hline Bronchopulmonary hygiene & 30 & 26 & 32 & 41 & 39 & 33 \\
\hline
\end{tabular}


Table 4. Use of Respiratory Care Protocols Stratified by Hospital Size (105 Units, Manager Survey)

\begin{tabular}{|c|c|c|c|c|c|c|}
\hline \multirow{3}{*}{ Protocol } & \multicolumn{6}{|c|}{ Level of Use (\%) } \\
\hline & \multicolumn{2}{|c|}{ Never } & \multicolumn{2}{|c|}{ Infrequent } & \multicolumn{2}{|c|}{ Frequent } \\
\hline & Small Hospital & Large Hospital & Small Hospital & Large Hospital & Small Hospital & Large Hospital \\
\hline \multicolumn{7}{|l|}{ Condition-specific protocols } \\
\hline Asthma & 33 & 18 & 26 & 33 & 40 & 50 \\
\hline COPD & 25 & 24 & 33 & 27 & 42 & 49 \\
\hline ARDS & 44 & 32 & 37 & 16 & 20 & 51 \\
\hline Hypoxemia & 29 & 15 & 29 & 18 & 41 & 68 \\
\hline Pneumonia & 38 & 23 & 18 & 28 & 44 & 50 \\
\hline \multicolumn{7}{|l|}{ Treatment-specific protocols } \\
\hline Noninvasive ventilation therapy & 28 & 24 & 33 & 15 & 38 & 62 \\
\hline Oxygen titration and discontinuation & 17 & 8 & 30 & 14 & 53 & 78 \\
\hline Ventilator weaning & 33 & 5 & 19 & 28 & 48 & 67 \\
\hline Bronchopulmonary hygiene & 31 & 25 & 43 & 28 & 26 & 47 \\
\hline
\end{tabular}

Table 5. Analysis of Stakeholder Impressions of the Hospital and the Perceived Impact of Respiratory Care Protocol Use

\begin{tabular}{|c|c|c|c|c|c|c|c|c|c|}
\hline \multirow{2}{*}{$\begin{array}{l}\text { Impact of Respiratory Care } \\
\text { Protocol Use on: }\end{array}$} & \multicolumn{3}{|c|}{ Physicians $(n=79), \%$} & \multicolumn{3}{|c|}{ RT Managers $(n=105), \%$} & \multicolumn{3}{|c|}{$\operatorname{RTs}(n=571), \%$} \\
\hline & Lower & No Change & Higher & Lower & No Change & Higher & Lower & No Change & Higher \\
\hline Cost of care & 66 & 31 & 3 & 90 & 9 & 1 & 75 & 20 & 5 \\
\hline Quality of care & 3 & 32 & 66 & 1 & 9 & 90 & 1 & 17 & 82 \\
\hline RT job satisfaction & 1 & 10 & 89 & 2 & 4 & 94 & 2 & 6 & 92 \\
\hline RT work load & 18 & 28 & 54 & 42 & 33 & 24 & 37 & 32 & 31 \\
\hline Physician job satisfaction & 0 & 49 & 51 & 1 & 45 & 54 & 4 & 44 & 52 \\
\hline Physician work load & 51 & 42 & 7 & 68 & 26 & 6 & 61 & 29 & 10 \\
\hline Patient satisfaction & 1 & 42 & 56 & 2 & 15 & 83 & 2 & 11 & 87 \\
\hline
\end{tabular}

with having organizational support $(\mathrm{OR}=5.46, P=.07)$. ORs for other features (including RT and RT manager support, use of quality practices, and hospital and unit characteristics) did not differ significantly from 1 (all $P>.10$ ). Factors significantly associated with high use of protocols included physician support $(\mathrm{OR}=18.20, P<.01)$ and $\mathrm{RT}$ support $(\mathrm{OR}=16.92, P=.04)$, with high use of protocols marginally associated with use of quality practices in a hospital $(\mathrm{OR}=15.05, P=.06)$.

\section{Discussion}

The main findings of this study are: (1) Use of 9 specific types of respiratory therapy protocols was associated with specific hospital characteristics, such that larger hospitals tended to use specific protocols more frequently than smaller hospitals, but teaching hospitals and non-teaching hospitals used specific respiratory care protocol types similarly. (2) All stakeholder groups agreed that use of respi- ratory care protocols conferred benefits (ie, lowering cost, improving patient satisfaction, and enhancing quality of respiratory care delivered), but disagreed regarding the impact of protocols on RT work load. Physicians believed that protocol use increased RT work load, and RT managers believed that protocol use decreased RT work load. RTs themselves were approximately equally divided regarding the impact of protocols on their own work load. (3) Multivariate analysis indicated that the features most strongly associated with protocol use (vs non-use) were physician support for their use and the use of a highquality hospital information system. Likewise, RT support and additional hospital quality practices were associated with high use (vs low use) of protocols, but not with use versus non-use.

Our survey data indicate that physician support is important for both protocol adoption and high levels of use. Although RT support was not associated with the adoption of respiratory protocols, among hospital units that had 
Table 6. Results of Logistic Regression Analysis of Various Hospital Features Associated With Respiratory Care Protocol Use and Frequency

\begin{tabular}{|c|c|c|c|c|}
\hline \multirow{2}{*}{ Hospital Feature } & \multicolumn{4}{|c|}{ Odds Ratio } \\
\hline & $\begin{array}{l}\text { Group } 1 \\
\text { (Users)* }\end{array}$ & $P$ & $\begin{array}{c}\text { Group } 2 \\
(\text { High Use }) \dagger\end{array}$ & $P$ \\
\hline Manager support & 0.31 & .27 & 0.13 & .13 \\
\hline Physician support & 3.68 & $.001 \ddagger$ & 18.20 & $.001 \div$ \\
\hline RT support & 2.97 & .13 & 16.92 & $.04 \div$ \\
\hline Organizational support & 5.46 & $.07 \ddagger$ & 0.29 & .38 \\
\hline Quality practices & 0.50 & .34 & 15.05 & $.06 \div$ \\
\hline Information systems & 2.33 & $.03 \ddagger$ & 0.88 & .84 \\
\hline Teaching & 0.64 & .61 & 0.35 & .33 \\
\hline Hospital size & 1.00 & .11 & 1.00 & .39 \\
\hline $\mathrm{ICU}$ & 3.44 & .11 & 4.83 & .26 \\
\hline Neonatal ICU & 5.32 & .13 & 1.78 & .73 \\
\hline Emergency department & 2.81 & .23 & 0.31 & .13 \\
\hline Pseudo $\mathrm{R}^{2}$ & 0.41 & & .59 & \\
\hline$n$ & 105 & & 66 & \\
\hline $\begin{array}{l}* \text { Users compared with non-use } \\
\dagger \text { High use compared with low } \\
\ddagger \text { Features showing significant } \\
\text { RT = respiratory therapist }\end{array}$ & $\begin{array}{l}\text { f respiratory } \\
\text { of respiratory } \\
\text { ciations }(P<\end{array}$ & $\begin{array}{l}\text { protocol } \\
\text { re protoce } \\
\text { ) or stron }\end{array}$ & rends $(P<.10)$ & \\
\hline
\end{tabular}

protocols, RT support was significantly associated with their clinical use. In addition, quality practices were not associated with adoption, but among hospital units using protocols, those units with general quality practices tended to have high levels of protocol use.

Finally, the observation that adoption of a high-quality hospital information system was associated with overall use of protocols but not with frequency of use suggests that having an information system is a necessary but not sufficient condition for protocol use. Adopting a respiratory care protocol may not be possible without an integrated hospital information system to track patterns and outcomes of utilization. However, once protocols were in use, the information system did not exert an influence on protocol use frequency.

This study extended available knowledge regarding the adoption and use of respiratory care protocols by assessing various hospital features associated with protocol use and also by multivariate analysis of correlates of protocol use. Prior randomized controlled trials in single-hospital settings showed that protocol use was associated with enhanced clinical quality and allocation of respiratory care. ${ }^{5,10}$ To our knowledge, only one previous study evaluated correlates of respiratory care protocol use. ${ }^{11}$ In that study, a change-avid environment in the RT department was positively associated with use of respiratory care protocols, but neither hospital characteristics nor features of stakeholder support were evaluated. In our study, the broader analysis of features associated with frequency and use of protocols permits a fuller understanding of features needed for successful implementation of respiratory care protocols and the hierarchy of the conditions that must be met. For example, physician support and the availability of a high-quality hospital information system appear to be necessary conditions. Similarly, support by RTs appears to be an important determinant of the frequency of protocol use, thereby affirming the impact of empowerment on first-line employees. ${ }^{16,17}$ This finding confirms a substantial body of literature from sectors other than health care that shows that first-line worker empowerment is associated with enhanced organizational performance. For example, 2 metaanalyses demonstrated that individual-level empowerment is associated with greater individual and team performance measures. ${ }^{17,18}$ Specifically, when employees have higher levels of empowerment, they perceive a greater impact on their jobs, which in turn drives higher levels of overall job performance. ${ }^{17,19}$ In addition, higher levels of employee empowerment have been shown to raise employee job satisfaction, increase organizational commitment, and decrease turnover intent. ${ }^{16,17}$

Several limitations of this study warrant mention. First, despite extensive recruitment efforts, the number of participating physicians $(n=79)$ remained relatively small compared with other stakeholder groups ( $n=105$ for RT managers and $n=571$ for RTs). Also, the number of hospitals studied (44) was relatively small. In addition, the method by which hospitals elected to participate and RT managers agreed to facilitate the study may reflect a selection bias toward participation-prone institutions and staff. Finally, our survey did not include nurses, whose opinions regarding the use of respiratory care protocols would complement the perspectives of physicians, RT managers, and RTs. The limitations of small sample size and possible selection bias may decrease the generalizability of our findings.

Second, because the study is descriptive, the results are necessarily hypothesis-generating and require validation in a separate analysis in which an a priori hypothesis is confirmed in a separate cohort of hospitals. As an example, to confirm the role of physician support and information system use in protocol adoption, future studies should select different hospitals on the basis of physician support for protocols and the presence versus absence of a highquality hospital information system and then measure differences regarding protocol use in these disparate hospital groups.

A third limitation of the study is that it depended on subjective reports of protocol use, cost, and quality of care by surveyed stakeholders rather than on use of actual objective measures of cost and quality (eg, hospital readmission rates, sentinel event frequencies) or actual protocol use. Self-reported data may clearly be subject to bias. 


\section{Patterns and Factors in Respiratory Care Protocol Use}

\section{Conclusions}

In summary, this study examines the use of respiratory protocols across multiple hospitals. Although confirmation of some of the findings in hypothesis-testing studies is warranted, our results clarify existing patterns and perceptions of protocol use, which may impact protocol implementation and benchmarks.

\section{REFERENCES}

1. Kacmarek RM, Durbin CG, Barnes TA, Kageler WV, Walton JR, O'Neil EH. Creating a vision for respiratory care in 2015 and beyond. Respir Care 2009;54(3):375-389.

2. Bureau of Labor Statistics, United States Department of Labor. Occupational outlook handbook, 2014-15 Edition, Respiratory Therapists. http://www.bls.gov/ooh/healthcare/respiratory-therapists.htm. Accessed September 21, 2014.

3. Blackwood B, Alderdice F, Burns K, Cardwell C, Lavery G, O'Halloran P. Use of weaning protocols for reducing duration of mechanical ventilation in critically ill adult patients: Cochrane systematic review and meta-analysis. BMJ 2011;342:c7237.

4. Harbrecht BG, Delgado E, Tuttle RP, Cohen-Melamed MH, Saul MI, Valenta CA. Improved outcomes with routine respiratory therapist evaluation of non-intensive-care-unit surgery patients. Respir Care 2009;54(7):861-867.

5. Kollef MH, Shapiro SD, Silver P, St John RE, Prentice D, Sauer S, et al. A randomized, controlled trial of protocol-directed versus physician-directed weaning from mechanical ventilation. Crit Care Med 1997;25(4):567-574.

6. Kollef MH, Shapiro SD, Clinkscale D, Cracchiolo L, Clayton D, Wilner R, Hossin L. The effect of respiratory therapist-initiated treatment protocols on patient outcomes and resource utilization. Chest 2000;117(2):467-475.

7. Modrykamien AM, Stoller JK. The scientific basis for protocoldirected respiratory care. Respir Care 2013;58(10):1662-1668.
8. Stoller JK. The effectiveness of respiratory care protocols. Respir Care 2004;49(7):761-765.

9. Stoller JK, Skibinski CI, Giles DK, Kester EL, Haney DJ. Physicianordered respiratory care vs. physician-ordered use of a respiratory therapy consult service. Chest 1996;110(2):422-429.

10. Stoller JK, Mascha EJ, Kester L, Haney D. Randomized controlled trial of physician-directed versus respiratory therapy consult servicedirected respiratory care to adult non-ICU inpatients. Am J Respir Crit Care Med 1998;158(4):1068-1075.

11. Stoller JK, Kester L, Roberts VT, Orens DK, Babic MD, Lemin ME, et al. An analysis of features of respiratory therapy departments that are avid for change. Respir Care 2008;53(7):871-884.

12. Boyer KK, Gardner JW, Schweikhart S. Process quality improvement: an examination of general vs. outcome specific climate and practices in hospitals. J Oper Manage 2012;30(4):325-339.

13. Goldstein SM, Naor M. Linking publicness to operations management practices: a study of quality management practices in hospitals. J Oper Manage 2005;23(2):209-228.

14. Tucker AL. An empirical study of system improvement by frontline employees in hospital units. Manuf Serv Oper Manage 2007;9(4): 492-505.

15. Hair J, Black W, Babin B, Anderson R. Multivariate data analysis, 7th edition. Upper Saddle River, New Jersey: Prentice Hall; 2010; 317-342.

16. Kraimer ML, Seibert SE, Liden RC. Psychological empowerment as a multidimensional construct: a test of construct validity. Educ Psychol Meas 1999;59(1):127-142.

17. Seibert SE, Wang G, Courtright SH. Antecedents and consequences of psychological and team empowerment in organizations: a metaanalysis review. J Appl Psychol 2011;96(5):981-1003.

18. Maynard MT, Gilson LL, Mathieu JE. Empowerment-fad or fab? A multilevel review of the past two decades of research. J Manage 2012;38(4):1231-1281.

19. Spreitzer GM, Kizilos MA, Nason SW. A dimensional analysis of the relationship between psychological empowerment and effectiveness, satisfaction, and strain. J Manage 1997;23(5):679-704.

This article is approved for Continuing Respiratory Care Education credit. For information and to obtain your CRCE

(free to AARC members) visit www.rcjournal.com

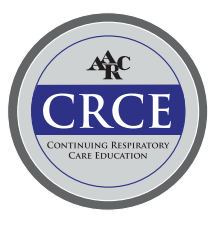

